\title{
Deletion of mu opioid receptors reduces palatable solution intake in a mouse model of binge eating Gaëlle Awad ${ }^{a}$, Laurie-Anne Roeckel ${ }^{a}$, Dominique Massotte ${ }^{b}$, Mary C. Olmstead ${ }^{\mathrm{C}}$ and Katia Befort ${ }^{\mathrm{a}}$
}

\begin{abstract}
Binge eating in humans is driven by hedonic properties of food, suggesting that brain reward systems may contribute to this behaviour. We examined the role of mu opioid receptors (MOP) in binge eating by examining sweet solution intake in mice with genetic deletion of the MOP. Wildtype and MOP knockout mice had 4 hours access to food in the home cage combined with limited ( 4 hours) access to sucrose $(17.1 \% \mathrm{w} / \mathrm{v})$ or saccharin $(0.09 \% \mathrm{w} / \mathrm{v})$, or continuous ( 24 hours) access to sucrose. Only limited access groups exhibited binge intake, measured as increased solution consumption during the first hour. Knockout mice consumed less solution and food during the first hour as well as less food each day compared with wildtype mice. Limited access groups consumed more food and gained more weight than continuous access groups, and the effect was magnified in saccharin-consuming mice. Indeed, the increased food consumption in animals given limited access to saccharin was so excessive that caloric intake
\end{abstract}

\section{Introduction}

Binge eating disorder (BED), the most prevalent of all eating disorders (Kessler et al., 2013; Solmi et al., 2016), is associated with detrimental health outcomes including obesity (Grucza et al., 2007; Stojek and MacKillop, 2017) and several mental health conditions (Javaras et al., 2008; Solmi et al., 2016). Treatments for BED are not widely available and generally ineffective, partly because the aetiology of the disorder is poorly understood (Hutson et al., 2018).

Emerging evidence points to alterations in brain reward circuits in BED patients (Balodis et al., 2015; Kessler et al., 2016), matching reports of increased dopamine release in the nucleus accumbens (NAcc) of rats following sucrose bingeing (Rada et al., 2005). In the context of motivated behaviours, disruptions in mesolimbic dopamine function would impact binge eating by altering 'wanting' of food rewards (Kelley and Berridge, 2002).

In contrast, the 'liking' component of natural rewards is mediated through opioid systems, specifically the mu opioid receptor (MOP) (Castro and Berridge, 2014). For instance, intra-NAcc injections of MOP agonists produce hyperphagia of highly palatable food (Zhang and Kelley, 2002; Nogueiras et al., 2012; Katsuura and Taha, 2014); opioid and selective MOP antagonists have the opposite of this group was significantly higher than either of the sucrose groups (limited or continuous access). Within this group, females consumed more food per bodyweight than males, highlighting important sex differences in feeding behaviours under restricted access schedules. Behavioural Pharmacology 31: 249-255 Copyright ( 2019 Wolters Kluwer Health, Inc. All rights reserved.

Behavioural Pharmacology 2020, 31:249-255

Keywords: binge eating disorder, feeding, mu opioid receptor, motivation, reward, saccharin

aLaboratoire de Neurosciences Cognitives et Adaptatives (LNCA), Centre de la Recherche Nationale Scientifique, Université de Strasbourg Faculté de Psychologie, ${ }^{b}$ Centre de la Recherche Nationale Scientifique, Université de Strasbourg, Institut des Neurosciences Cellulaires et Intégratives (INCl), Strasbourg, France and ${ }^{\mathrm{C}}$ Department Psychology, Centre for Neuroscience Studies, Queen's University, Kingston, ON, Canada

Correspondence to Mary C. Olmstead, Department of Psychology, Queen's University, Kingston, ON K7L 3N6, Canada

E-mail: olmstead@queensu.ca

Received 6 January 2019 Accepted as revised 5 June 2019

effect (Ward et al., 2006; Sahr et al., 2008; Katsuura and Taha, 2014). MOPs appear to be linked, specifically, to hedonic responses associated with preferred foods (Giuliano et al., 2012; Nogueiras et al., 2012; Ostlund et al., 2013), which may explain why blockade of MOPs reduces subjective ratings and ad libitum intake of preferred foods in BED patients (Drewnowski et al., 1995; Ziauddeen et al., 2013). Together, clinical and preclinical data suggest that MOPs may contribute to binge eating by regulating the hedonic aspects of palatable food.

We tested the role of MOPs in binge eating by assessing intake of highly palatable food (sucrose or saccharin) and regular chow in mice lacking MOPs. Binge eating, defined as excessive consumption within a discrete period of time, was induced using a limited access protocol (Corwin et al., 2011) adapted for mice (Yasoshima and Shimura, 2015). We focussed, exclusively on sweet solutions, rather than sweet/fat combinations, as the two commodities induce distinct neural and behavioural adaptations (Avena, 2010).

\section{Methods}

Subjects

Twelve male and 12 female mice lacking MOP receptors and their wildtype controls (wildtype female $n=30$; male 
$n=24)$ were single housed under standard light, temperature, and humidity conditions (12-hour light-dark cycle, $22 \pm 2^{\circ} \mathrm{C}, 55 \pm 10 \%$ humidity). Knockout mice were generated by homologous recombination (Matthes et al., 1996) on a genetic background of 50\% C57/BL6J:50\% $129 \mathrm{svP}$ as. Mice weighed $23-46.7 \mathrm{~g}$ at the start of the experiment, ranging in age from four months to approximately one year (wildtype: 17.7-32.8 weeks; MOP knockout: $18.5-58.8$ weeks).

Research was conducted in accordance with the European Communities Council Directive of 22 September 2010 (directive 2010/63/UE). Experiments were approved by the local ethical committee (Comité Régional d'Ethique en Matière d'Expérimentation Animale de Strasbourg CREMEAS) and findings are reported following the ARRIVE Guidelines for experiments involving animals.

\section{Sucrose consumption}

The protocol for sucrose consumption, including solution concentrations and access periods, was based on a procedure that induces sucrose bingeing in mice (Yasoshima and Shimura, 2015). Briefly, MOP knockout and wildtype mice were randomly assigned to one of three access conditions: limited sucrose (4hours sucrose and food, 4SUC/4F); limited saccharin (4 hours saccharin and food, $4 \mathrm{SAC} / 4 \mathrm{~F}$ ); or continuous sucrose (24 hours sucrose and 4 hours food, $24 \mathrm{SUC} / 4 \mathrm{~F}$ ). As far as possible, sex, age, and initial weight were counterbalanced across groups. Sucrose and saccharin were presented at concentrations that are equally preferred in mice $(17.1$ and $0.09 \% \mathrm{w} / \mathrm{v}$, respectively).

Mice were habituated to single housing and water presentation in two sipper tubes in the home cage for a minimum of six days. Over the next 14 days, beginning 2 hours into the light cycle, mice were presented with standard chow and solution according to their group assignment. Water was available ad libitum. Solution $(\mathrm{mL})$ and chow (g) intake were measured 1, 4, and 24 hours following presentation. Binge intake was assessed as significantly higher solution consumption during the first hour of access. Animals were weighed daily and sacrificed at the end of the intermittent access period.

\section{Statistical analyses}

Solution and food intake were analysed using a Linear Mixed Model (LMM) analysis (Winter, 2013) in which consumption (solution, food, kilocalories) was assessed as a function of group, day, sex, and weight. LMM analyses accounts for both fixed and random effects, the latter reflecting individual differences in baseline intake. Degrees of freedom were calculated using the WelchSatterthwaite equation (pooled degrees of freedom) as there is no assumption that underlying population variances are equal (Satterthwaite, 1946). Group differences across sessions were analysed using a likelihood ratio test
(LRT) (Luke, 2017) that compares goodness of fit of two models: the full model against one that combines two groups of interest into a single group. Statistically significant effects indicate that the two groups are distinct.

\section{Results}

Figure 1 shows that limited access to a sweet solution induces binge intake in both wildtype and MOP knockout mice, confirmed by a significant escalation of sucrose intake across 14 days for the $4 \mathrm{SUC} / 4 \mathrm{~F}$ wildtype $\quad\left(t_{(1,424)}=7.906 ; \quad P<0.001\right), \quad 4 \mathrm{SUC} / 4 \mathrm{~F} \quad \mathrm{MOP}$ knockout $\left(t_{(1,399)}=4.545 ; P<0.001\right), 4$ SAC/4F wildtype $\left.t_{(1,412)}=3.878 ; P<0.001\right)$, and $4 \mathrm{SAC} / 4 \mathrm{~F}$ MOP knockout $\left(t_{(1,403)}^{(1,412)}=2.890 ; P=0.003\right)$ groups (Fig. 1a). Intake during the first hour of access did not increase across sessions in wildtype or knockout mice given continuous access to sucrose (i.e., 24SUC/4F groups). LRT analysis revealed that the rate of increased solution intake during the first hour was higher in wildtype compared with MOP knockout mice given limited access to sucrose $\left[X^{2}(2)=12.174\right.$; $P=0.002)$ and saccharin $\left[X^{2}(2)=8.8796 ; P=0.01\right]$.

Chow consumption during the first hour also increased across sessions in all groups [4SUC/4F MOP knockout $\left(t_{(1,622)}=2.688 ; P=0.007\right) ; 4 \mathrm{SAC} / 4 \mathrm{~F}$ wildtype $\left(t_{(1,639)}=4.983\right.$; $P<0.001)$ and MOP knockout $\left(t_{(1,625)}=5.238 ; P<0.001\right)$; 24SUC/4F wildtype $\left(t_{(1,622)}=2.501 ; P=0.012\right)$ and MOP knockout $\left.\left(t_{(1,624)}=3.284 ; P<0.001\right)\right]$, with the exception of $4 \mathrm{SUC} / 4 \mathrm{~F}$ wildtype mice $\left(t_{(1,644)}=1.100 ; P=0.244\right)$. The rate of increased chow intake during the first hour was significantly different in wildtype and MOP knockout mice in the 4SUC/4F group $\left[X^{2}(2)=11.291 ; P=0.004\right]$, but not in the other two groups: $4 \mathrm{SAC} / 4 \mathrm{~F}([(2)=1.342 ; P=0.511]$ and 24SUC/4F $\left[X^{2}(2)=5.935 ; P=0.051\right]$ (Fig. 1b).

In order to assess overall differences in consumption, we conducted an analysis of variance (ANOVA) on all measures, using access group and genotype as between subjects' factors. This yielded a generally consistent pattern of results with no significant group $\mathrm{X}$ genotype interaction for any measure of intake or body weight $\left(P_{\mathrm{s}}>0.05\right)$, although wildtype mice drank more water than MOP knockout mice $\left(F_{(1,61)}=5.686 ; P=0.020\right)$ (Fig. 1c).

Figure 1d shows that daily sweet solution intake did not differ between wildtype and MOP knockout groups $\left[4 \mathrm{SUC} / 4 \mathrm{~F} \quad\left(X^{2}(2)=2.437, \quad \mathrm{df}=2 ; \quad P=0.296\right) ; \quad 4 \mathrm{SAC} / 4 \mathrm{~F}\right.$ $\left(X^{2}(2)=5.775 ; P=0.056\right)$; and $24 \mathrm{SUC} / 4 \mathrm{~F}\left(X^{2}(2)=1.1306\right.$; $P=0.568)]$. LMM analysis also revealed significant escalation of daily solution intake across sessions, only in limited access groups [4SUC/4F wildtype $\left(t_{(1,238)}=9.877\right.$; $P<0.001)$ and MOP knockout $\left(t_{(1,224)}=6.479 ; P<0.001\right)$; 4SAC/4F wildtype $\left(t_{(1,228)}=9.990 ; P<0.001\right)$ and MOP knockout $\left.\left(\mathrm{t}_{(1,227)}=7.092 ; P<0.001\right)\right]$.

All six groups showed significant increases in daily chow consumption across sessions, verified by LMM analysis in wildtype $\left[4 \mathrm{SUC} / 4 \mathrm{~F}\left(t_{(1,601)}=3.699 ; P<0.001\right) ; 4 \mathrm{SAC} / 4 \mathrm{~F}\right.$ 

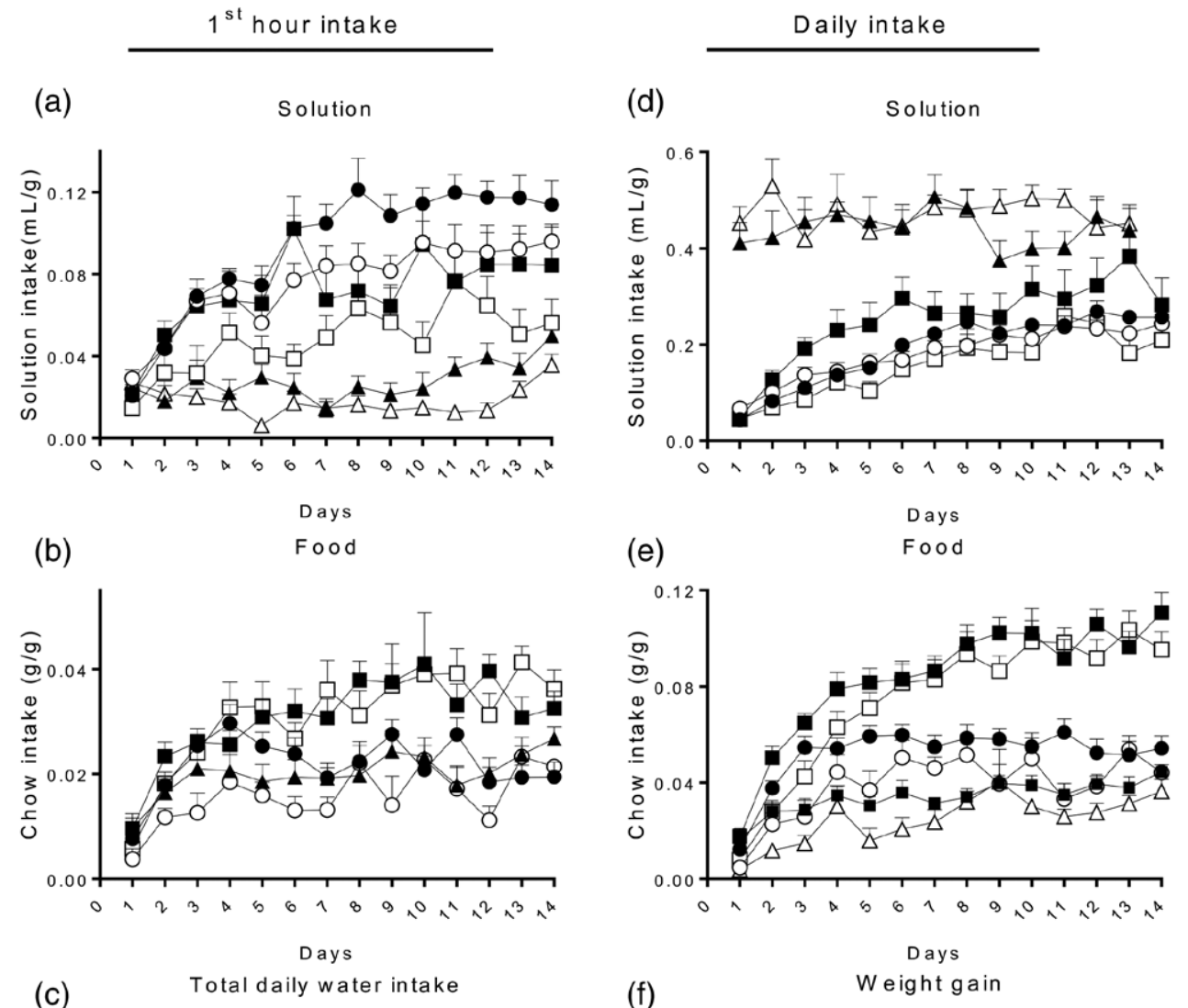

(c)

Total daily water intake

(f)
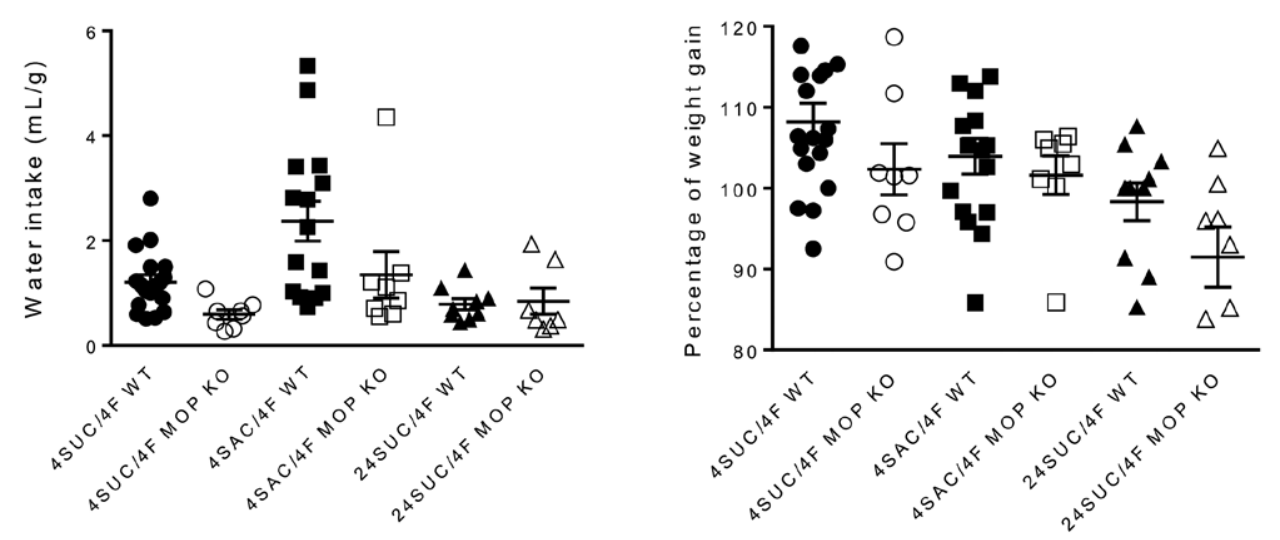

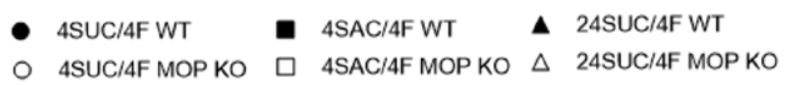

Limited access to sweet solution produces binge intake. Mice were given daily access to sucrose, saccharin, and food for 14 days as follows: $4 \mathrm{SUC} / 4 \mathrm{~F}=4$ hours access to sucrose and food; $4 \mathrm{SAC} / 4 \mathrm{~F}=4$ hours access to saccharin and food; $24 \mathrm{SUC} / 4 \mathrm{~F}=24 \mathrm{hours}$ access to sucrose and 4 hours access to food. Data are presented as mean intake per body weight $(\mathrm{mL} / \mathrm{g}$ and $\mathrm{g} / \mathrm{g})$ of solution (a) and (d) or food (b) and (e) during the first hour of access (a) and (b) and over each 24-hour period (d) and (e). Total water intake (c) and percentage weight gain from baseline (f) were calculated across the 14 days. Error bars represent SEM. MOP knockout, mu opioid knockout; WT, wildtype.

$\left(t_{(1,591)}=9.418 ; \quad P<0.001\right) ; \quad 24 \mathrm{SUC} / 4 \mathrm{~F} \quad\left(t_{(1,574)}=3.450\right.$; $P<0.001)]$ and MOP knockout $\left[4 \mathrm{SUC} / 4 \mathrm{~F}\left(t_{(1,574)}=4,071\right.\right.$; $P<0.001) ; 4$ SAC $/ 4 \mathrm{~F}\left(t_{(1.578)}=9.909 ; P<0.001\right) ; 24$ SUC $/ 4 \mathrm{~F}$ $\left.\left(t_{(1,572)}=4.130 ; P<0.001\right)\right]$ groups. The rate of daily chow intake was higher in wildtype groups with limited access to sucrose $\left(X^{2}(2)=10.112 ; P=0.006\right)$ and saccharin $\left(X^{2}(2)=6.492 ; P=0.039\right)$ (Fig. 1e). In addition, wildtype mice gained more weight than MOP knockout mice 
$\left(F_{(1,62)}=6.927 ; P=0.010\right)$, with the two limited access groups ( $4 \mathrm{SUC} / 4 \mathrm{~F}$ and $4 \mathrm{SAC} / 4 \mathrm{~F}$ ) gaining more than the continuous access $(24 \mathrm{SUC} / 4 \mathrm{~F})$ group $\left(F_{(2,62)}=7.374\right.$; $P<0.001)$ (Fig. 1f).

Data presented in Fig. 2 show that MOP knockout mice consumed less sweet solution $\left(F_{(1,62)}=12.090 ; P<0.001\right)$ and food $\left(F_{(1,62)}=9.594 ; P=0.002\right)$ than wildtype mice during the first hour of access (Fig. 2a and b), as well as less total food $\left(F_{(1.54)}=11.449 ; P<0.001\right)$ across sessions (Fig. 2e). Total daily intake of sweet solution did not differ across genotypes $\left(F_{(1,62)}=0.19 ; \quad P=0.665\right)$ (Fig. 2d). In addition, solution intake during the first

Fig. 2

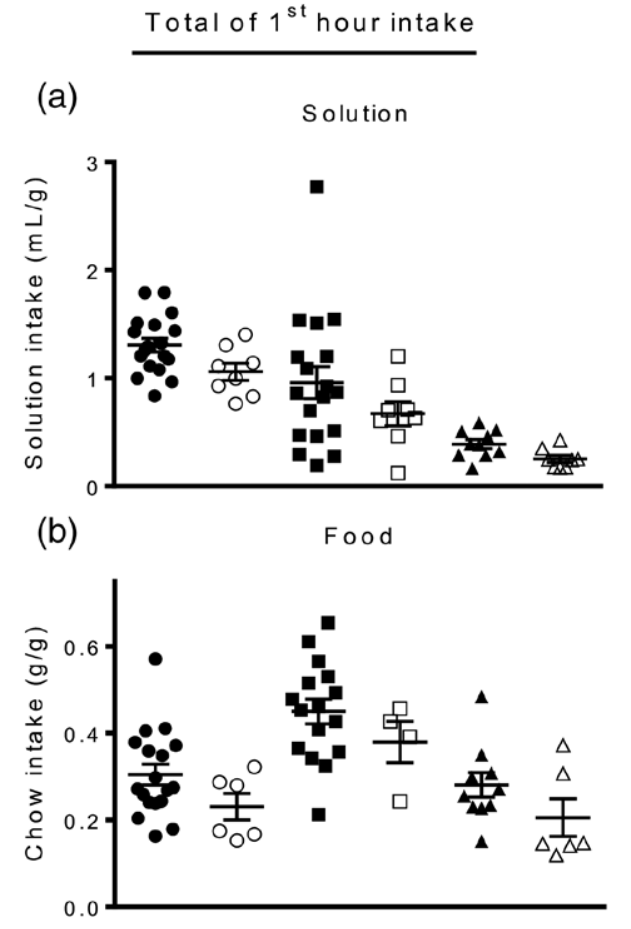

(d) Solution

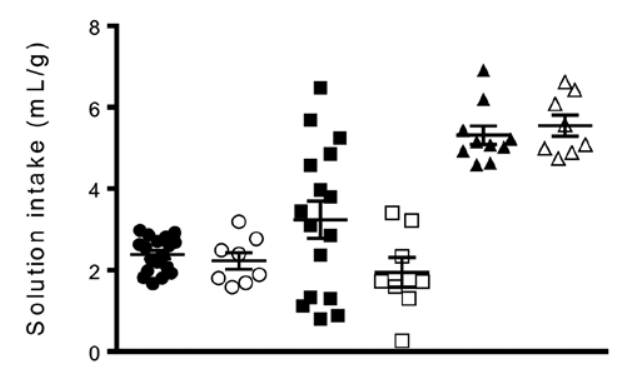

(e)

Food

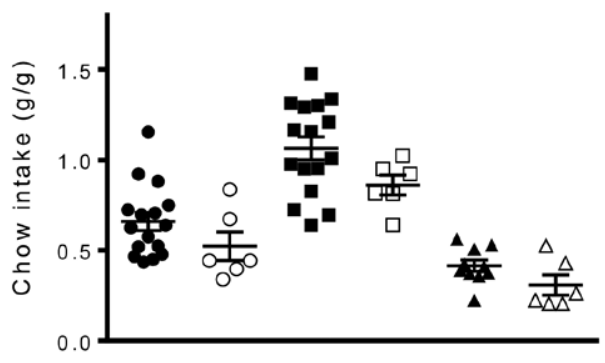

(c)

(f) Calories
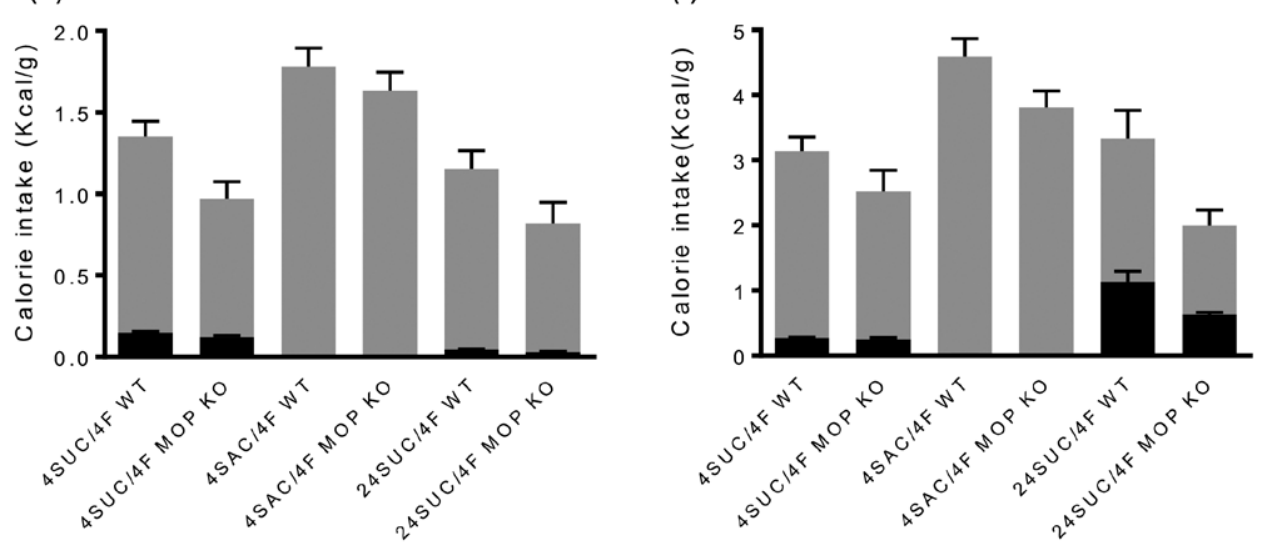

$\begin{array}{llllll}- & \text { 4SUC/4F WT } & \boldsymbol{a} & \text { 4SAC/4F WT } & \boldsymbol{\Delta} & \text { 24SUC/4F WT } \\ \text { O } & \text { 4SUC/4F MOP KO } & \square & \text { 4SAC/4F MOP KO } & \Delta & \text { 24SUC/4F MOP KO }\end{array}$

Limited access to saccharin increases total calories consumed. Mice were given daily access to sucrose, saccharin, and food for 14 days as follows: $4 \mathrm{SUC} / 4 \mathrm{~F}=4$ hours access to sucrose and food; $4 \mathrm{SAC} / 4 \mathrm{~F}=4$ hours access to saccharin and food; $24 \mathrm{SUC} / 4 \mathrm{~F}=24 \mathrm{hours}$ access to sucrose and 4 hours access to food. Data are presented as mean total solution (a) and (d) or food (b) and (e) intake per body weight (mL/g and $\mathrm{g} / \mathrm{g}$ ), summed across 14 sessions. Intake was measured during the first hour of access (a) and (b) and over each 24 -hour period (d) and (e). Caloric intake per body weight was summed across 14 sessions for the first hour of intake (c) and for each 24 -hour period (f). Error bars represent SEM. MOP knockout, mu opioid knockout; WT, wildtype. 
hour was significantly higher in both limited access groups $\left(F_{(2,62)}=28.217 ; P<0.001\right)$, whereas food intake was increased only in the $4 \mathrm{SAC} / 4 \mathrm{~F}$ group $\left(F_{(2,62)}=24.384\right.$; $P<0.001)$. Total daily intake followed a similar pattern with the continuous access group $(24 \mathrm{SUC} / 4 \mathrm{~F})$ consuming more sweet solution than the limited access groups $\left(F_{(2,62)}=49.381 ; P<0.001\right)$, and the $4 \mathrm{SAC} / 4 \mathrm{~F}$ group consuming more food $\left(F_{(2.54)}=47.367 ; P<0.001\right)$ and water $\left(F_{(2,61)}=10.329 ; P<0.001\right)$ than the other two groups.

Increased food intake in the saccharin group could simply reflect compensation for the lack of calories in artificial sweetener. To assess this, we compared total calorie intake across groups using the following calculations: chow $=3.952 \mathrm{Kcal} / \mathrm{g}$; sucrose solution $=0.114 \mathrm{Kcal} /$ $\mathrm{mL}$; saccharin $=0.00366 \mathrm{Kcal} / \mathrm{mL}$. Analysis of these data yielded a significant group effect, with the saccharin group consuming more calories than either sucrose group in the first hour $\left(F_{(2,54)}=13.124 ; P<0.001\right) \quad($ Fig. $2 \mathrm{c})$ and across the entire session $\left(F_{(2,54)}=29.324 ; P<0.001\right)$ (Fig. 2f). Again, wildtype mice consumed more calories than MOP knockout mice $\left(F_{(1,54)}=10.121 ; P=0.002\right)$ (Fig. 2c and f).

We also examined sex differences in all intake measures (data not shown) using LMM analysis, revealing that wildtype females in the $4 \mathrm{SAC} / 4 \mathrm{~F}$ group consumed more solution $\left(X^{2}(2)=10.170 ; \quad P=0.006\right)$ and chow $\left(X^{2}(2)=13.753 ; P=0.001\right)$ than males in the first hour, as well as more chow across the session $\left(X^{2}(2)=33.666\right.$; $P<0.001)$. There were no sex differences in any intake measure of wildtype animals given access to sucrose (i.e., $4 \mathrm{SUC} / 4 \mathrm{~F}$ or $24 \mathrm{SUC} / 4 \mathrm{~F}$ ). ANOVA on total consumption of both genotypes across sessions confirmed that females in the $4 \mathrm{SAC} / 4 \mathrm{~F}$ group consumed more chow than males in the first hour $\left(F_{(1)}=9.343 ; P=0.006\right)$, and over the 4-hour access period $\left({ }^{F} F_{(1)}=33.333 ; P<0.001\right)$. In the latter analysis, both the genotype $\left(F_{(1)}=7.160 ; P=0.015\right)$ and sex X genotype interaction $\left(F_{(1)}=4.685 ; P=0.044\right)$ were statistically significant.

\section{Discussion}

We successfully reproduced a model of binge intake in mice (Yasoshima and Shimura, 2015), manifested as excessive consumption of a sweet solution within the first hour of access. Mice given limited access to food, but not sucrose (i.e., 24SUC/4F group), did not display binge intake, confirming that restriction of a palatable substance contributes to this maladaptive behaviour. In our preliminary experiments (data not shown), mice given limited access to sucrose and unlimited access to food (i.e., 4SUC/24F) also displayed binge intake, although it was reduced compared with the group with restricted access to both commodities (4SUC/4F). Food restriction, therefore, may exacerbate hyperphagic responses to palatable food. This could occur through physiological stress responses which, themselves, induce binge eating in mice (Micioni Di Bonaventura et al., 2014). Human studies support a relationship between stress and binge eating in that chronically high levels of glucocorticoids may trigger intake of 'comfort' foods (Dallman et al., 2003) and stressful life events initiate both binge eating and cortisol production in BED patients (Gluck, 2006).

Our study also confirmed reduced consumption of food and sweet solution in mice lacking MOPs (Ostlund $e t$ al., 2013). The effect was particularly apparent in our measure of binge intake (first hour solution consumption), fitting evidence that MOPs play a role in hedonic responses of binge eating in humans (Cambridge et al., 2013). This genotype profile is also revealed under conditions of food deprivation (Ostlund et al., 2013) or increased effort to obtain a reward (Roberts et al., 2000; Papaleo et al., 2007). In contrast, MOP knockout and wildtype mice show no differences in food intake or seeking responses when access to palatable food is increased or continuous (Tabarin et al., 2005; Papaleo et al., 2007). These differences could reflect a critical role of MOPs in stress responses (LaBuda et al., 2000; Ide et al., 2010), which would be increased under food restriction. A MOP contribution to binge eating may occur through interactions with orexigenic neurons (Castro and Berridge, 2017), which amplify hedonic or liking responses to a sweet solution (Castro and Berridge, 2014). This is supported by evidence that BED patients exhibit a loss of MOP availability in the NAcc (Majuri et al., 2017), an area described as a 'hedonic hotspot' in food reward (Castro et al., 2015). Our findings are in general agreement with studies showing decreased consumption of palatable food with MOP antagonism (Taha, 2010; Giuliano and Cottone, 2015), although this effect may not involve the NAcc (Lardeux et al., 2015). We also observed that MOP knockout mice gained less weight than their wildtype controls, which could reflect altered physiological and metabolic responses to food (Wen $e t$ al., 2009) as well as increased energy homeostasis and disrupted hunger cues (Tabarin et al., 2005). Indeed, MOPs may have a marginal role in satiation processes in that anticipatory or 'wanting' response for food are not affected by food deprivation in MOP knockout mice (Kas et al., 2004). Finally, we cannot rule out the possibility that alterations in functional brain connectivity, characteristic of MOP knockout mice (Mechling et al., 2016), contribute to altered behavioural responses in this genotype.

Somewhat surprisingly, mice given limited access to saccharin ate more food than mice with either limited or continuous sucrose access, even beyond an expected compensation for caloric differences in natural and artificial sweeteners. The increased food intake in saccharin bingeing animals was not dependent on the presence or absence of MOPs, but may be linked to sex differences: binge intake of saccharin escalated more quickly across sessions in females than males, whereas all other intake measures were similar in the two sexes. This matches 
previous findings that female, but not male, rats exhibit an increased preference for noncaloric, but not caloric, sweeteners (Valenstein et al., 1967). These findings emphasize the need to critically evaluate the continued and widespread use of artificial sweeteners, particularly as abstinence from saccharin (Aoyama et al., 2014), like sucrose (Grimm et al., 2013), elicits craving in rats and nonnutritive sweeteners induce physiological changes mimicking those of nutritive compounds (Tucker and Tan, 2017). Furthermore, although we did not observe this effect in our mice, noncaloric sweeteners can induce higher levels of weight gain than natural sugars (Feijó et al., 2013), possibly through an increase in orexigenic peptides (Furudono et al., 2006; Gaysinskaya et al., 2011).

In sum, rodent models of sucrose bingeing provide valuable insight into the behavioural and biological underpinnings of maladaptive eating. Restricting access to palatable food increases the propensity to binge, leading to alterations in reward processing (Smail-Crevier et al., 2018) as well as neurophysiological changes associated with compulsive responding (Maracle et al., 2019). We now identify a contribution of MOPs to binge eating, findings that may translate to clinical treatment (Ziauddeen et al., 2013). Our study also points to potential pitfalls in substituting artificial for natural sweeteners, and highlights the need to understand gender differences in eating behaviours.

\section{Acknowledgements}

Université de Strasbourg, Investissements d'Avenir Idex, Centre National de la Recherche Scientifique (CNRS), Projet International de Coopération Scientifique (PICS), and Natural Sciences and Engineering Research Council of Canada (NSERC).

\section{Conflicts of interest}

There are no conflicts of interest.

\section{References}

Aoyama K, Barnes J, Grimm JW (2014). Incubation of saccharin craving and within-session changes in responding for a cue previously associated with saccharin. Appetite 72:114-122.

Avena NM (2010). The study of food addiction using animal models of binge eating. Appetite 55:734-737.

Balodis IM, Grilo CM, Potenza MN (2015). Neurobiological features of binge eating disorder. CNS Spectr 20:557-565.

Cambridge VC, Ziauddeen H, Nathan PJ, Subramaniam N, Dodds C, Chamberlain $\mathrm{SR}$, et al. (2013). Neural and behavioral effects of a novel mu opioid receptor antagonist in binge-eating obese people. Biol Psychiatry 73:887-894.

Castro DC, Berridge KC (2014). Opioid hedonic hotspot in nucleus accumbens shell: mu, delta, and kappa maps for enhancement of sweetness 'liking' and 'wanting'. J Neurosci 34:4239-4250.

Castro DC, Berridge KC (2017). Opioid and orexin hedonic hotspots in rat orbitofrontal cortex and insula. Proc Natl Acad Sci U S A 114:E9125-E9134.

Castro DC, Cole SL, Berridge KC (2015). Lateral hypothalamus, nucleus accumbens, and ventral pallidum roles in eating and hunger: interactions between homeostatic and reward circuitry. Front Syst Neurosci 9:90.

Corwin RL, Avena NM, Boggiano MM (2011). Feeding and reward: perspectives from three rat models of binge eating. Physiol Behav 104:87-97.

Dallman MF, Pecoraro N, Akana SF, La Fleur SE, Gomez F, Houshyar H, et al. (2003). Chronic stress and obesity: a new view of 'comfort food'. Proc Natl Acad Sci U S A 100:11696-11701.
Drewnowski A, Krahn, DD, Demitrack MA, Nairn K, Gosnell BA (1995). Naloxone, an opiate blocker, reduces the consumption of sweet high-fat foods in obese and lean female binge eaters. Am J Clin Nutr 61:1206-1212.

Feijó FM, Ballard CR, Foletto KC, Batista BAM, Neves AM, Ribeiro MFM, Bertoluci MC (2013). Saccharin and aspartame, compared with sucrose, induce greater weight gain in adult Wistar rats, at similar total caloric intake levels. Appetite 60:203-207.

Furudono Y, Ando C, Yamamoto C, Kobashi M, Yamamoto T (2006). Involvement of specific orexigenic neuropeptides in sweetener-induced overconsumption in rats. Behav Brain Res 175:241-248.

Gaysinskaya VA, Karatayev O, Shuluk J, Leibowitz SF (2011). Hyperphagia induced by sucrose: relation to circulating and CSF glucose and corticosterone and orexigenic peptides in the arcuate nucleus. Pharmacol Biochem Behav 97:521-530.

Giuliano C, Cottone P (2015). The role of the opioid system in binge eating disorder. CNS Spectr 20:537-545.

Giuliano C, Robbins TW, Nathan PJ, Bullmore ET, Everitt BJ (2012). Inhibition of opioid transmission at the $\mu$-opioid receptor prevents both food seeking and binge-like eating. Neuropsychopharmacology 37:2643-2652.

Gluck ME (2006). Stress response and binge eating disorder. Appetite 46:26-30.

Grimm JW, Weber R, Barnes J, Koerber J, Dorsey K, Glueck E (2013). Brief exposure to novel or enriched environments reduces sucrose cue-reactivity and consumption in rats after 1 or 30 days of forced abstinence from self-administration. Plos One 8:e54164.

Grucza RA, Przybeck TR, Cloninger CR (2007). Prevalence and correlates of binge eating disorder in a community sample. Compr Psychiatry 48:124-131.

Hutson PH, Balodis IM, Potenza MN (2018). Binge-eating disorder: clinical and therapeutic advances. Pharmacol Ther 182:15-27.

Ide S, Sora I, Ikeda K, Minami M, Uhl GR, Ishihara K (2010). Reduced emotional and corticosterone responses to stress in mu-opioid receptor knockout mice. Neuropharmacology 58:241-247.

Javaras KN, Pope HG, Lalonde JK, Roberts JL, Nillni YI, Laird NM, et al. (2008). Co-occurrence of binge eating disorder with psychiatric and medical disorders. J Clin Psychiatry 69:266-273.

Kas MJ, van den Bos R, Baars AM, Lubbers M, Lesscher HM, Hillebrand JJ, et al. (2004). Mu-opioid receptor knockout mice show diminished food-anticipatory activity. Eur J Neurosci 20:1624-1632.

Katsuura Y, Taha SA (2014). Mu opioid receptor antagonism in the nucleus accumbens shell blocks consumption of a preferred sucrose solution in an anticipatory contrast paradigm. Neuroscience 261:144-152.

Kelley AE, Berridge KC (2002). The neuroscience of natural rewards: relevance to addictive drugs. J Neurosci 22:3306-3311.

Kessler RC, Berglund PA, Chiu WT, Deitz AC, Hudson JI, Shahly V, et al. (2013). The prevalence and correlates of binge eating disorder in the world health organization world mental health surveys. Biol Psychiatry 73:904-914.

Kessler RM, Hutson PH, Herman BK, Potenza MN (2016). The neurobiological basis of binge-eating disorder. Neurosci Biobehav Rev 63:223-238.

LaBuda CJ, Sora I, Uhl GR, Fuchs PN (2000). Stress-induced analgesia in mu-opioid receptor knockout mice reveals normal function of the delta-opioid receptor system. Brain Res 869:1-5.

Lardeux S, Kim JJ, Nicola SM (2015). Intermittent-access binge consumption of sweet high-fat liquid does not require opioid or dopamine receptors in the nucleus accumbens. Behav Brain Res 292:194-208.

Luke SG (2017). Evaluating significance in linear mixed-effects models in R. Behav Res Methods 49:1494-1502.

Majuri J, Joutsa J, Johansson J, Voon V, Alakurtti K, Parkkola R, et al. (2017). Dopamine and opioid neurotransmission in behavioral addictions: a comparative PET study in pathological gambling and binge eating. Neuropsychopharmacology 42:1169-1177.

Maracle AC, Normandeau CP, Dumont ÉC, Olmstead MC (2019). Dopamine in the oval bed nucleus of the stria terminalis contributes to compulsive responding for sucrose in rats. Neuropsychopharmacology 44: 381-389.

Matthes HW, Maldonado R, Simonin F, Valverde O, Slowe S, Kitchen I, et al. (1996). Loss of morphine-induced analgesia, reward effect and withdrawal symptoms in mice lacking the mu-opioid-receptor gene. Nature 383:819-823.

Mechling AE, Arefin T, Lee HL, Bienert T, Reisert M, Ben Hamida S, et al. (2016). Deletion of the mu opioid receptor gene in mice reshapes the reward-aversion connectome. Proc Natl Acad Sci U S A 113:11603-11608.

Micioni Di Bonaventura MV, Ciccocioppo R, Romano A, Bossert JM, Rice KC, Ubaldi $M$, et al. (2014). Role of bed nucleus of the stria terminalis corticotrophin-releasing factor receptors in frustration stress-induced binge-like palatable food consumption in female rats with a history of food restriction. $J$ Neurosci 34:11316-11324. 
Nogueiras R, Romero-Picó A, Vazquez MJ, Novelle MG, López M, Diéguez C (2012). The opioid system and food intake: homeostatic and hedonic mechanisms. Obes Facts 5:196-207.

Ostlund SB, Kosheleff A, Maidment NT., Murphy NP (2013). Decreased consumption of sweet fluids in $\mu$ opioid receptor knockout mice: a microstructural analysis of licking behavior. Psychopharmacology (Berl) 229: 105-113.

Papaleo F, Kieffer BL, Tabarin A, Contarino A (2007). Decreased motivation to eat in mu-opioid receptor-deficient mice. Eur J Neurosci 25:3398-3405.

Rada P, Avena NM, Hoebel BG (2005). Daily bingeing on sugar repeatedly releases dopamine in the accumbens shell. Neuroscience 134: 737-744.

Roberts AJ, McDonald JS, Heyser CJ, Kieffer BL, Matthes HW, Koob GF, Gold $\mathrm{LH}$ (2000). Mu-opioid receptor knockout mice do not self-administer alcohol. J Pharmacol Exp Ther 293:1002-1008.

Sahr AE, Sindelar DK, Alexander-Chacko JT, Eastwood BJ, Mitch CH, Statnick MA (2008). Activation of mesolimbic dopamine neurons during novel and daily limited access to palatable food is blocked by the opioid antagonist LY255582. Am J Physiol Regul Integr Comp Physiol 295:R463-R471.

Satterthwaite FE (1946). An approximate distribution of estimates of variance components. Biometrics 2:110-114.

Smail-Crevier RL, Maracle AC, Wash SIJ, Olmstead MC (2018). Binge-like intake of sucrose reduces the rewarding value of sucrose in adult rats. Physiol Behav 194:420-429.

Solmi F, Hotopf M, Hatch SL, Treasure J, Micali N (2016). Eating disorders in a multi-ethnic inner-city UK sample: prevalence, comorbidity and service use. Soc Psychiatry Psychiatr Epidemiol 51:369-381.
Stojek MMK, MacKillop J (2017). Relative reinforcing value of food and delayed reward discounting in obesity and disordered eating: a systematic review. Clin Psychol Rev 55:1-11.

Tabarin A, Diz-Chaves Y, Chaves YD., Carmona Mdel C, Catargi B, Zorrilla EP et al. (2005). Resistance to diet-induced obesity in mu-opioid receptor-deficient mice: evidence for a 'thrifty gene'. Diabetes 54:3510-3516.

Taha SA (2010). Preference or fat? Revisiting opioid effects on food intake. Physiol Behav 100:429-437.

Tucker RM, Tan SY (2017). Do non-nutritive sweeteners influence acute glucose homeostasis in humans? A systematic review. Physiol Behav 182:17-26.

Valenstein ES, Kakolewski JW, Cox VC (1967). Sex differences in taste preference for glucose and saccharin solutions. Science 156:942-943.

Ward HG, Nicklous DM, Aloyo VJ, Simansky KJ (2006). Mu-opioid receptor cellular function in the nucleus accumbens is essential for hedonically driven eating. Eur J Neurosci 23:1605-1613.

Wen T, Peng B, Pintar JE (2009). The MOR-1 opioid receptor regulates glucose homeostasis by modulating insulin secretion. Mol Endocrinol 23:671-678.

Winter B (2013). Linear models and linear mixed effects models in R with linguistic applications. https://doi.org/http://arxiv.org/pdf/1308.5499.pdf

Yasoshima Y, Shimura T (2015). A mouse model for binge-like sucrose overconsumption: contribution of enhanced motivation for sweetener consumption. Physiol Behav 138:154-164.

Zhang M, Kelley AE (2002). Intake of saccharin, salt, and ethanol solutions is increased by infusion of a mu opioid agonist into the nucleus accumbens. Psychopharmacology (Berl) 159:415-423.

Ziauddeen H, Chamberlain SR, Nathan PJ, Koch A, Maltby K, Bush M, et al. (2013). Effects of the mu-opioid receptor antagonist GSK1521498 on hedonic and consummatory eating behaviour: a proof of mechanism study in binge-eating obese subjects. Mol Psychiatry 18:1287-1293. 